\title{
Perfil lipídico y ensayos de las actividades antioxidante, insecticida y antialimentaria de la esponja marina Iotrochota birotulata (Iotrochotidae: Demospongiae)
}

\author{
Orlando Pastrana Franco, Gilmar Santafé Patiño \& Emy Sánchez Romero \\ Grupo de Química de los Productos Naturales, Universidad de Córdoba, Cra. 6 No 74-103 Montería, Colombia; \\ orlandojosepf@gmail.com, gsantafe@correo.unicordoba.edu.co, emyluzsr@gmail.com
}

\author{
Recibido 28-II-2018. C Corregido 20-VIII-2018. Aceptado 28-I-2019.
}

\begin{abstract}
Lipid profile and assays of the antioxidant, insecticide and antifeedant activities of the marine sponge Iotrochota birotulata (Iotrochotidae: Demospongiae). It is estimated that three quarters of earth's surface is occupied by the oceans. This constitutes the habitat of a large number of species of flora and fauna. As part of the marine organisms, the most studied biochemical phylum are Porifera, Cnidaria and more recently Ascomycota, from which a large number of chemical compounds have been isolated and identified. These have shown different types of biological activities, mainly cytotoxic, bactericidal and antioxidant. In this research the marine sponge Iotrochota birotulata collected in Punta Bello-Córdoba in the Colombian Caribbean was studied, and its lipid profile from the analysis of the corresponding mass spectra of its constituent compounds was determined, 19 fatty acids were identified, which are reported for the first time for this specie, besides 10 sterols were identified. Fatty acids with carbon chains between C15 and C27 were found, showing a wide structural diversity, which is characteristic of the porifera phylum. The sterols showed structures mainly with nucleus $\Delta^{5}$ and $\Delta^{7}$, which are the most abundant in sponges. Moderate antioxidant activity was found in the stabilization of the radical cation ABTS $+\bullet$ and low activity in the stabilization of the radical $\mathrm{DPPH} \bullet$, the highest inhibition value was found in the aqueous extract with an $\mathrm{IC}_{50}$ de $43.9 \mu \mathrm{g} / \mathrm{ml}$ against the radical cation ABTS $+\bullet$, showing that $I$. birotulata can produce compounds with moderate antioxidant activity. In the insecticidal activity test, larval affectation was found in methanolic and aqueous extracts at all concentrations and at all times of exposure evaluated against Spodoptera frugiperda, it was also determined that these extracts induce an antifeedant effect on the larvae as part of the mechanism insecticide. The optimal conditions and exposure times were determined for the best efficiency of the assay, which were $3000 \mu \mathrm{g} / \mathrm{ml}$ and $48 \mathrm{~h}$ for the methanolic extract and $2000 \mu \mathrm{g} / \mathrm{ml}$ and $24 \mathrm{~h}$ for the aqueous extract, respectively. In conclusion, the evaluated extracts of the $I$. birotulata showed moderate antioxidant activity and good and interesting insecticidal and antifeedant activities.
\end{abstract}

Key words: Iotrochota birotulata; antioxidant activity; insecticide activity; antifeeding activity; lipid profile; Spodoptera frugiperda.

Pastrana Franco, O., Santafé Patiño, G. \& Sánchez Romero, E. (2019). Perfil lipídico y ensayos de las actividades antioxidante, insecticida y antialimentaria de la esponja marina Iotrochota birotulata (Iotrochotidae: Demospongiae). Revista de Biología Tropical, 67(1), 213-223.

Las esponjas son animales simples, multicelulares y sésiles sin tejidos verdaderos u órganos, habitan todo tipo de ambiente marino, desde los mares en los polos hasta aguas templadas y tropicales siendo frecuentemente más abundantes y diversas en el trópico. Las esponjas constituyen un grupo de gran éxito evolutivo que se ha ramificado en más de 8000 especies y son en cierta forma un recurso biológico desconocido (Quirós, Medrano, \& Santafé, 2017). Estos organismos son una de las fuentes principales para el aislamiento 
de productos naturales alcanzando un $38 \%$ de todos los compuestos naturales marinos reportados, conociéndose más de 5300 sustancias estructuralmente diferentes y con amplios espectros de actividades biológicas, entre las que se destacan las antimicrobianas, neurotóxicas, citotóxicas y antimitóticas, entre otras (Blunt, Copp, Munro, Northcote, \& Prinsep, 2017; Guevara, Amaro, Fariñas, López, \& D'Armas, 2016).

En trabajos previos realizados en I. birotulata se logró la identificación y caracterización de tres esteroles: ergostga-6 $\beta$-5hidroxi-4,24(28)dien-3-ona, ergosta-6 $\alpha$-hidroxi-4,24(28)-dien3-ona y ergosta-6 $\alpha$-hidroxi-4,22-E-dien-3-ona (Li, Deng, Fu, Li, \& Proksh, 2005). También se identificó el compuesto derivado de la bromotirosina: 1,3-dibromo-5-\{2-[(p-hidroxifenil) acetamido]etil\}-2-[3-(3-metil-2-butanamido) propoxi]benceno (Constantino, Fattorusso, \& Mangoni, 1994), el cual mostró potencial antitumoral contra varias líneas celulares (Márquez, Márquez, Martínez, \& Thomas, 2011). En este sentido, se logró evidenciar que los extractos en solución de etanol y agua (1:1) de esta esponja, actúan significativamente en la fosforilación de la enzima ERK, afectando el proceso de señalización de las células SW-13 de carcinoma adrenal humano (Brown, Kesler, Neary, \& Fishman, 2001). También, extractos de diferentes polaridades de la esponja $I$. birotulata exhibieron potencial citotóxico y genotóxico frente a las líneas celulares $\mathrm{CHO}$ K1 y Jurkat de cáncer de mama (De la Ossa, López, Márquez, Martínez, \& Márquez, 2016). Asimismo, actividad antimicrobiana frente a cepas de las bacterias Staphylococcus aureus y Escherichia coli, y del hongo Candida albicans (Galeano \& Martínez, 2007; Jiang et al., 2008), y actividad antitumoral frente a línea celular A549 de cáncer de pulmón por parte de una fracción de ácidos grasos (Márquez, Márquez, Martínez, \& Thomas, 2011).

En otras investigaciones, se informa acerca del aislamiento de otro tipo de compuestos, los ecdisteroides, que son sustancias que inducen la apoptosis en células de melanoma ocasionando una inhibición del mecanismo de producción de ceramidas (Salma et al., 2009). En el presente trabajo se describe el perfil lipídico de la esponja marina I. birotulata, recolectada en Punta Bello, Córdoba-Colombia, utilizando principalmente técnicas cromatográficas y espectrometría de masas. También se describe la actividad antioxidante, insecticida y antialimentaria de los extractos obtenidos a partir de I. birotulata.

\section{MATERIALES Y MÉTODOS}

Material biológico: Los especímenes de la esponja marina I. birotulata fueron recolectados en Punta Bello, Caribe colombiano $\left(9.25^{\circ} \mathrm{N}-75.43^{\circ} \mathrm{W}\right)$. El material fue sometido a congelación hasta el posterior tratamiento. Los especímenes recolectados fueron ubicados taxonómicamente y un ejemplar de colección se encuentra en el laboratorio de Química de los Productos Naturales de la Universidad de Córdoba con el código PNM-P13.

Obtención de los extractos: El material recolectado de $I$. birotulata fue cortado en pedazos y sometido a percolación en metanol $(\mathrm{MeOH})$ durante 5 días (este proceso se realizó tres veces), luego se filtró y se concentró a presión reducida obteniendo el extracto metanólico, el cual fue sometido a fraccionamiento por reparto empleando mezclas de cloroformo:agua $(1: 1)$, la fase orgánica fue separada y concentrada a presión reducida hasta obtener el extracto clorofórmico, mientras que la fase acuosa se liofilizó obteniendo el extracto acuoso (Pastrana, Santafé, \& Torres, 2016).

Obtención de la fracción lipídica: El extracto clorofórmico fue sometido a cromatografía en columna (CC) usando sistemas de elución desde Hexano:AcOEt (7:1) hasta Metanol $(\mathrm{MeOH})$, las subfracciones obtenidas fueron monitoreadas por cromatografía de capa delgada (CCD). Como reveladores fueron utilizados luz ultravioleta, vapores de yodo y el reactivo de Liebermann-Burchard. Las subfracciones con Rf similares al ácido oleico y al colesterol fueron reunidas y concentradas a presión 
reducida para su estudio por cromatografía de gases acoplado a espectrometría de masas (CGEM) (Pastrana, Santafé, \& Torres, 2016).

El experimento se realizó en un Cromatógrafo de Gases Agilent $6890 \mathrm{~N}$ con detector selectivo de masas Agilent 5973N. Se utilizó una columna DB-5MS con un volumen de inyección $3 \mu$ en modo Splitless. Para la identificación de los compuestos registrados se utilizaron las librerías NIST02.L, NIST5a.L y NIST98.L.

\section{Ensayos de actividad antioxidante:}

Método de radical DPPH•. Se preparó una solución madre de DPPH• (2,2-difenil-1-picrilhidrazil) que contiene $150 \mathrm{mg} \mathrm{DPPH} / 7 \mathrm{ml}$ $\mathrm{MeOH}$, la cual fue guardada en la oscuridad por $24 \mathrm{~h}$. Luego se tomaron pequeñas alícuotas, las cuales fueron diluidas con $\mathrm{MeOH}$ hasta obtener una absorbancia de $0.300 \pm 0.05$ a una $\lambda=517$ $\mathrm{nm}$, ajustando con un blanco de $\mathrm{MeOH}$. Para la evaluación de la actividad antioxidante, se mezclaron $40 \mu \mathrm{l}$ del patrón de muestra disuelto en dimetilsulfóxido (DMSO) con $1960 \mu \mathrm{l}$ del radical DPPH• previamente preparado. La mezcla se dejó a temperatura ambiente durante 30 min en la oscuridad y posteriormente se leyó la absorbancia en el espectrofotómetro a 517 $\mathrm{nm}$. Para el blanco de muestra se mezclaron $40 \mu \mathrm{l}$ del patrón de muestra con $1960 \mu \mathrm{l}$ de $\mathrm{MeOH}$ y para la referencia se mezclaron 40 $\mu 1$ de DMSO con $1960 \mu \mathrm{l}$ del radical DPPH• (Santafé, Pastrana, \& Quirós, 2016). Todas las mediciones fueron realizadas por triplicado y el porcentaje de Inhibición a esa concentración fue calculado utilizando la ecuación 1. Luego se graficó el \% inhibición vs la concentración determinando el porcentaje de inhibición medio $\left(\mathrm{IC}_{50}\right)$ por interpolación lineal.

$\%$ Inhibición $=\left[1-\left(\frac{A_{\text {muestra }}-A_{\text {blanco }}}{A_{\text {referencia }}}\right)\right] * 100 \%$ (1)

Método del catión radical ABTS+•. Se preparó una solución madre de radical ABTS• (ácido 2,2'-azino-bis(3-etilbenzotiazolin-6-sulfónico)) (17.5 mg de ABTS• en $9.9 \mathrm{ml} \mathrm{de} \mathrm{H}_{2} \mathrm{O}$ estéril). Luego se tomaron $34 \mathrm{mg}$ de persulfato de potasio $\left(\mathrm{S}_{2} \mathrm{O}_{8} \mathrm{~K}_{2}\right)$ diluidos en $1 \mathrm{ml}$ de agua destilada. De estas soluciones preparadas se tomaron $9.9 \mathrm{ml}$ de solución de ABTS • (3.5 $\mathrm{mM})$ y $0.1 \mathrm{ml}$ de solución de persulfato de potasio $(125 \mathrm{mM})$ y se mezclaron. Posteriormente la mezcla fue guardada en la oscuridad por $12 \mathrm{~h}$, luego se tomaron pequeñas alícuotas que fueron diluidas con un buffer fosfato de $\mathrm{pH}$ 7.4 hasta obtener una absorbancia ajustada de $0.700 \pm 0.05$ a una $\lambda=732 \mathrm{~nm}$, ajustando con un blanco de buffer fosfato. Para la evaluación de la actividad antioxidante se mezclaron 40 $\mu 1$ del patrón de muestra en dimetilsulfóxido (DMSO) con $1960 \mu$ de catión radical ABTS+• previamente preparado, la mezcla fue incubada a temperatura ambiente durante $30 \mathrm{~min}$ en la oscuridad y posteriormente se leyó la absorbancia en el espectrofotómetro a $732 \mathrm{~nm}$. Para el blanco de muestra se mezclaron $40 \mu \mathrm{l}$ del patrón de muestra con $1960 \mu \mathrm{l}$ de buffer de fosfato y para la referencia se mezclaron $40 \mu \mathrm{l}$ de DMSO con $1960 \mu 1$ de catión radical ABTS+• (Santafé, Pastrana, \& Quirós, 2016). Todas las mediciones fueron realizadas por triplicado y el porcentaje de inhibición a esa concentración fue calculado utilizando la ecuación 1. Luego se graficó el \% Inh vs la concentración para determinar el porcentaje de inhibición medio $\left(\mathrm{IC}_{50}\right)$ por interpolación lineal.

Actividad insecticida $y$ antialimentaria: El ensayo se desarrolló contra larvas de Spodoptera frugiperda, obtenidas de insectos maduros de la misma especie previamente recolectados de un cultivo de algodón libre de agroquímicos desarrollado en la Universidad de Córdoba. Los insectos maduros se mantuvieron en frascos plásticos sobre un abanico de papel y alimentados con solución acuosa de miel al $30 \%$ y cerveza por medio de algodones impregnados hasta de deposición de los huevos, los cuales fueron transferidos a cajas de Petri con hojas tiernas de algodón e incubados a $25{ }^{\circ} \mathrm{C}$ y $75 \%$ de humedad relativa.

Para el ensayo se depositaron en cajas de Petri discos foliares de algodón lavados con agua destilada y secados a la sombra, posteriormente fueron impregnados por $5 \mathrm{~min}$ con 
soluciones de los extractos metanólico y acuoso a concentraciones de 1000, 2000, 3000, 4000 y $5000 \mu \mathrm{g} / \mathrm{ml}$. Como control negativo fueron utilizados discos foliares impregnados con solvente (agua:metanol 95:5) y como testigo absoluto discos foliares lavados con agua. Posteriormente fueron depositadas las larvas, las cuales tenían entre 6 y $9 \mathrm{~h}$ de haber eclosionado, luego fueron incubadas a temperatura ambiente durante $72 \mathrm{~h}$. Todos los ensayos fueron realizados por cuadruplicado tomando los valores promedio correspondientes. La actividad insecticida se determinó haciendo lecturas de larvas afectadas a las 24, 48 y 72 h (Jiménez, Rodríguez, Murillo, Méndez, \& Rueda, 2013). Para evaluar el número de larvas afectadas se toman como criterios la no respuesta de las larvas a un estímulo punzante, su color amarillo, que sean pequeñas, el poco consumo y/o que estén muertas. Pasadas las $72 \mathrm{~h}$, se conservan las larvas en etanol al $70 \%$ para posteriormente medir su longitud (tamaño) y se tomaron los discos foliares de las hojas de algodón utilizadas en el ensayo midiendo el área de consumo de las larvas. La observación de las larvas en los ensayos de actividad insecticida y la medida de sus tamaños se efectuó utilizando una lentilla micrométrica acoplada a un estereoscopio. Para la determinación de la actividad antialimentaria se realizó la medición del área del consumo foliar empleando el software AUTOCAD y se calculó mediante la ecuación 2:

$$
E A A=\left[1-\left(\frac{T}{C}\right)\right] * 100(2)
$$

Siendo $\mathrm{T}$ el consumo foliar promedio para cada uno de los tratamientos y $\mathrm{C}$ el consumo foliar equivalente al control.

Análisis estadístico: Para la actividad antioxidante, todos los ensayos fueron realizados por triplicado tomando los valores promedios de los mismos. Para la actividad insecticida y antialimentaria, todos los ensayos fueron realizados por cuadruplicado tomando los valores promedios de los mismos. Para todas las actividades realizadas se determinó la correlación de los valores obtenidos mediante un análisis de varianza (ANOVA) y un ensayo Tukey con un nivel de significancia del $95 \%$.

\section{RESULTADOS}

Composición lipídica: El perfil lipídico de I. birotulata fue determinado mediante el análisis de los correspondientes espectros de masas de sus compuestos constituyentes, lográndose la identificación de 19 ácidos grasos, los cuales son reportados por primera vez para esta especie; además, fueron identificados 10 esteroles (Cuadro 1). Los ácidos grasos identificados mostraron longitudes de cadenas desde C15 hasta $\mathrm{C} 26$, donde el $31.52 \%$ de la mezcla total de ácidos grasos contienen cadenas saturadas, de este porcentaje, sólo el $17.80 \%$ corresponde a ácidos grasos con cadenas lineales saturadas y el $13.72 \%$ presenta cadenas saturadas ramificadas. El $61.01 \%$ de la mezcla total de ácidos grasos presentan cadenas insaturadas, y de este porcentaje, el $38.98 \%$ corresponde a los ácidos grasos de cadenas lineales insaturadas y el $22.03 \%$ presenta cadenas ramificadas insaturadas. Con relación al tipo de insaturación encontrado se obtuvo que los ácidos grasos monoinsaturados están presentes en un $37.6 \%$, los diinsaturados en un $5.10 \%$, y con un porcentaje menor equivalente al $14.54 \%$ aparecen los ácidos grasos poliinsaturados.

Por su parte, en el análisis de la distribución de los diferentes núcleos esteroidales encontrados, se observó que los esteroles con núcleo $\Delta^{5}-3 \beta$-Hidroxiandrosteno dominaron con un $55.97 \%$ (es el de más amplia distribución en la naturaleza), siguiéndole el núcleo $\Delta^{7}$-3 $\beta$-Hidroxiandrosteno con un $43.65 \%$. Teniendo en cuenta la presencia o ausencia de insaturaciones en la cadena lateral de los esteroles identificados, se observó que dominaron en igual proporción las cadenas insaturadas en el C22 $\left(\Delta^{22}\right)$ y C24 $\left(\Delta^{24}\right)$ con un $30 \%$ de abundancia cada una de ellas.

Los esteroles con cadena lateral saturada presentaron una abundancia del $20 \%$, mientras que los esteroles con insaturación en C24(28) $\left(\Delta^{24(28)}\right)$ y con doble insaturación $\left(\Delta^{22,24(28)}\right)$ 
CUADRO 1

Compuestos lipídicos identificados en I. birotulata

TABLE 1

Identified lipids compounds from I. birotulata

\begin{tabular}{|c|c|c|}
\hline Tiempo de retención (minutos) & Nombre & Porcentaje de abundancia relativa (\%) \\
\hline \multicolumn{3}{|c|}{ Ácidos grasos } \\
\hline 9.7 & Ácido tetradecanoico & 1.89 \\
\hline 13.1 & Ácido 7-metil-6-hexadecenoico & 5.26 \\
\hline 13.6 & Ácido 4,8,12-trimetiltridecanoico & 13.34 \\
\hline 14.6 & Ácido 9,12,13-trimetiltetradecanoico & 0.38 \\
\hline 15.3 & Ácido heptadecanoico & 1.47 \\
\hline 16.5 & Ácido 5,9-octadecadienoico & 2.27 \\
\hline 16.7 & Ácido 5-octadecenoico & 4.13 \\
\hline 16.8 & Ácido 9-octadecenoico & 3.74 \\
\hline 17.3 & Ácido octadecanoico & 12.25 \\
\hline 18.8 & Ácido nonadecanoico & 0.54 \\
\hline 19.5 & Ácido 5,8,11,14-eicosatetraenoico & 12.25 \\
\hline 19.6 & Ácido 5,8,11,14,17-eicosapentaenoico & 5.98 \\
\hline 20.0 & Ácido 5,11-eicosadienoico & 1.19 \\
\hline 20.1 & Ácido 11-eicosenoico & 1.13 \\
\hline 20.5 & Ácido eicosanoico & 1.65 \\
\hline 22.4 & Ácido 4,7,10,13,16,19-docosahexaenoico & 0.32 \\
\hline 26.2 & Ácido 5-tetracosenoico & 6.33 \\
\hline 27.4 & Ácido 5,9-pentacosadienoico & 1.64 \\
\hline 29.0 & Ácido 5,6-dimetil-8-hexacosenoico & 16.77 \\
\hline \multicolumn{3}{|c|}{ Esteroles } \\
\hline 31.4 & 24-etil-26-Nor-colest-5,22-dien-3 $\beta$-ol & 4.67 \\
\hline 32.8 & Colest-5-en-3 $\beta$-ol & 26.67 \\
\hline 33.9 & 24-metilcolest-7,22-dien-3ß-ol & 21.79 \\
\hline 34.0 & 24-metilencolest-7,22-dien-3 $\beta$-ol & 0.44 \\
\hline 35.0 & Colesta-5,24-dien-3 $\beta, 22 \xi$-diol & 12.28 \\
\hline 35.3 & 22, 23-dietil-26-Nor-Colesta-7,24-dien-3 $\beta$-ol & 0.22 \\
\hline 35.8 & 24-etilcolesta-5,22-dien-3 $\beta$-ol & 11.95 \\
\hline 37.0 & 24-etilcolesta-7-en-3 $\beta$-ol & 16.80 \\
\hline 37.2 & 23-etil-24-metil-26-Nor-colesta-7,24-dien-3 $\beta$-ol & 4.40 \\
\hline 37.6 & 23 -etil-24-metilen-26-Nor-colesta-5-en-3 $\beta, 22 \xi$-ol & 0.40 \\
\hline
\end{tabular}

estuvieron presentes en forma minoritaria con un $10 \%$ de abundancia. En cuanto a la distribución de los esteroles identificados de acuerdo con el número de átomos de carbono, se puede afirmar que los esteroles que presentaron mayor abundancia fueron los de 29 átomos de carbono mostrando un porcentaje equivalente al $50 \%$ y los esteroles de 27 átomos de carbono con $30 \%$, (estos tipos de esteroles son los de más amplía distribución en la naturaleza); los esteroles con 28 átomos de carbono presentaron un porcentaje de abundancia del $20 \%$, siendo los menos frecuentes.

Actividad antioxidante: Se encontró que los extractos evaluados presentaron actividad antioxidante moderada frente a la capacidad de estabilización del catión radical ABTS+•, con valores de $\mathrm{IC}_{50}$ de $52.6 \mu \mathrm{g} / \mathrm{ml}$ para el extracto metanólico, $62.3 \mu \mathrm{g} / \mathrm{ml}$ para el subextracto 
clorofórmico y $43.9 \mu \mathrm{g} / \mathrm{ml}$ para el subextracto acuoso (Cuadro 2). Sin embargo, no se encontró el mismo resultado frente a la capacidad de estabilización del radical $\mathrm{DPPH} \bullet$, con valores más altos de $\mathrm{IC}_{50}(139.8 \mu \mathrm{g} / \mathrm{ml}$ para el extracto metanólico, $>200 \mu \mathrm{g} / \mathrm{ml}$ para los otros).

\section{CUADRO 2}

Ensayos de actividad antioxidante de los extractos de I. birotulata

TABLE 2

Antioxidant activity assays of extracts of $I$. birotulata

\begin{tabular}{lcc}
\multicolumn{1}{c}{ Extracto } & \multicolumn{2}{c}{ Actividad Antioxidante } \\
& ABTS+• & DPPH \\
Metanólico & $52.6 \mu \mathrm{g} / \mathrm{ml}$ & $139.8 \mu \mathrm{g} / \mathrm{ml}$ \\
Clorofórmico & $62.3 \mu \mathrm{g} / \mathrm{ml}$ & $>200 \mu \mathrm{g} / \mathrm{ml}$ \\
Acuoso & $43.9 \mu \mathrm{g} / \mathrm{ml}$ & $>200 \mu \mathrm{g} / \mathrm{ml}$ \\
\hline
\end{tabular}

Actividad Insecticida: Se encontró que solo los extractos acuoso y metanólico presentaron inhibición del crecimiento larvario significativo en el ensayo preliminar, los cuales estuvieron por encima de $30 \%$ para ambos extractos. Por su parte, el extracto clorofórmico no superó el $15 \%$ de inhibición del crecimiento larvario en el ensayo preliminar siendo descartado para los posteriores ensayos (Cuadro 3 ).

Actividad antialimentaria: En cuanto al efecto antialimentario de los extractos frente a las larvas (Cuadro 4), se observó que esta característica está más ligada a la concentración de los extractos, encontrándose el mayor efecto a concentraciones de $5000 \mu \mathrm{g} / \mathrm{ml}$ para ambos extractos, los valores encontrados son más altos en relación con las demás concentraciones.

\section{DISCUSIÓN}

Las esponjas son organismos que están asociados normalmente con la abundante presencia de ácidos grasos de cadenas largas (> C24) con porcentajes que están por encima del

CUADRO 3

Ensayos de actividad insecticida de los extractos frente a las larvas de S. frugiperda

TABLE 3

Insecticide activity assays of extracts from the larva of $S$. frugiperda

\begin{tabular}{|c|c|c|c|c|c|c|c|c|c|c|c|c|c|}
\hline & \multirow{3}{*}{ Tiempo } & \multirow{3}{*}{ Testigo } & \multirow{3}{*}{ Control } & \multicolumn{5}{|c|}{ Extracto Metanólico } & \multicolumn{5}{|c|}{ Subextracto Acuoso } \\
\hline & & & & \multicolumn{10}{|c|}{ Concentración $\mu \mathrm{g} / \mathrm{ml}$} \\
\hline & & & & 1000 & 2000 & 3000 & 4000 & 5000 & 1000 & 2000 & 3000 & 4000 & 5000 \\
\hline \multirow[t]{3}{*}{ Larvas Afectadas } & $24 \mathrm{~h}$ & 0 & 0 & 2 & 5 & 8 & 13 & 14 & 5 & 15 & 17 & 16 & 20 \\
\hline & $48 \mathrm{~h}$ & & & 6 & 10 & 15 & 15 & 16 & 6 & 17 & 17 & 17 & 20 \\
\hline & $72 \mathrm{~h}$ & & & 7 & 13 & 16 & 18 & 18 & 8 & 17 & 18 & 19 & 20 \\
\hline \multicolumn{2}{|c|}{ Longitud de las Larvas (mm)* } & 2.5 & 2.5 & 2.0 & 2.2 & 2.0 & 2.2 & 1.9 & 2.0 & 1.7 & 1.9 & 1.8 & 1.8 \\
\hline
\end{tabular}

*La medición de las larvas fue realizada a las $72 \mathrm{~h}$.

\section{CUADRO 4}

EAA de los extractos metanólicos y acuoso frente a Spodoptera frugiperda

TABLE 4

EAA of methanolic and aqueous extracts from Spodoptera frugiperda

\begin{tabular}{lccccc} 
& \multicolumn{5}{c}{ Efecto Antialimentario (EAA) } \\
Extracto & 1000 & 2000 & 3000 & 4000 & 5000 \\
& 5.8 & 15.6 & 19.8 & 26.6 & 71.4 \\
Metanólico (\%) & 23.9 & 33.5 & 37.2 & 50.3 & 64.4 \\
Acuoso (\%) & &
\end{tabular}


$80 \%$ del total de ácidos grasos. Lo anterior se da principalmente en aquellas especies que viven en ambientes acuáticos profundos, ya que estos ácidos al ser constituyentes esenciales de las membranas celulares contribuyen con la resistencia del organismo a las altas presiones a las que están expuestos (Lawson, Bergquist \& Cambie, 1986). Sin embargo, en I. birotulata este porcentaje de ácidos grasos de cadena larga no superó el 30 \%. Esto podría deberse a que $I$. birotulata es un organismo que se encuentra principalmente en aguas de baja profundidad (Quirós, Medrano \& Santafé, 2017), por lo que posiblemente no requiere en sus membranas celulares ácidos grasos con cadenas laterales tan largas. Sin embargo, esto solo podría ser comprobado a través de un análisis comparativo de la longitud de las cadenas carbonadas de los ácidos grasos, presentes tanto en esponjas que viven en ambientes acuáticos profundos como las que viven en ambientes someros.

Se encontraron ácidos grasos de cadenas ramificadas como el ácido 4,8,12-trimetiltridecanoico, el ácido 9,12,13-trimetiltetradecanoico y el ácido 5,6-dimetil-8-hexacosenoico, característica que está de acuerdo con la observación general que relaciona al filum porífera con la producción de ácidos grasos con cadenas laterales ramificadas (Carballeira, Maldonado, \& Porras, 1987). En este aspecto, es interesante la presencia de la sustitución en el C13 del ácido 9,12,13-trimetiltetradecanoico, la cual es considerada como una sustitución inusual para las esponjas, pero que se ha evidenciado en especies del género Agelas, sin que se tenga una completa certeza de la función realizada por este tipo de compuestos químicos (Rodríguez et al., 2005), desde este punto de vista el género Iotrochota puede considerarse como productor de este tipo de ácidos. También se encontró un alto porcentaje de ácidos grasos monoinsaturados (AGMI), los cuales en otros organismos marinos están relacionados directamente con la fluidez de la membrana, comportamiento que les permite adaptarse a condiciones en el medio acuático (Drazen, Phleger, \& Nichols, 2008), por lo que en I. birotulata, los AGMI pueden asumir esta misma función.

En cuanto a la concentración de ácidos grasos poliinsaturados (AGPI), I. birotulata mostró un bajo porcentaje. Los AGPI modulan algunas enzimas cuya función es la protección de las células a los procesos de oxidación, llegando a ser utilizados en la prevención y tratamiento de enfermedades como diabetes mellitus (Pérez \& Guerrero, 2006). Por lo tanto, la baja concentración de AGPI en I. birotulata está directamente relacionada con su incapacidad para producir compuestos químicos con alta actividad antioxidante. Sin embargo, es de resaltar la presencia del ácido eicosapentaenoico (EPA) en este organismo, el cual ha sido empleado en el tratamiento dietario de pacientes con estado avanzado de diferentes tipos de cáncer mostrando resultados relevantes en la disminución de los procesos de degradación celular ocasionados por la enfermedad (Dewey, Baughan, Dean, Higgins, \& Johnson, 2012). Lo que podría suponer que los extractos de I. birotulata pueden llegar a exhibir actividad citotóxica frente a una o varias líneas de células tumorales.

Asimismo, se resalta la presencia del ácido docosahexaenoico, el cual ha mostrado potente actividad antimalárica con porcentajes de inhibición superiores al $90 \%$ frente a Plasmodium falciparum; que al igual que otros AGPI de las series $\mathrm{C} 20$ y C18 pero con menores actividades, causan principalmente hemólisis en las células sanguíneas del parásito o en ocasiones inhiben su síntesis de ácidos grasos (Carballeira, 2008). La presencia de este compuesto en I. birotulata le convierte en una posible fuente natural de metabolitos con potencial antimalárico.

De otra parte, los esteroles identificados en $I$. birotulata muestra un patrón más característico y acorde con la información relacionada con este tipo de compuestos en esponjas encontrándose principalmente núcleos $\Delta^{5}-3 \beta$ Hidroxiandrosteno y $\Delta^{7}-3 \beta$-Hidroxiandrosteno. Sin embargo, no se evidenció la presencia de esteroles con núcleo $\Delta^{0}$-3 $\beta$-Hidroxiandrostano, ni tampoco esteroles con núcleo $\Delta^{5,7}-3 \beta$ Hidroxiandrosteno, los cuales también son 
ampliamente abundantes en poríferos (Valle \& Santafé, 2009). Se evidenció que el esterol más abundante es el colesta-5-en-3 $\beta$-ol (colesterol) con un porcentaje de abundancia del $27 \%$, lo cual es consistente con el hecho de que este compuesto es el más ampliamente distribuido en los invertebrados marinos y que es un constituyente indispensable de las membranas celulares, así como el precursor de otros tipos de sustancias fisiológicamente importantes en estos organismos (Kanazawa, 2001).

La presencia de varios esteroles del tipo 24-metil y 24 etil en I. birotulata como es el caso del sitosterol, campesterol y algunos derivados (los cuales son más comunes en plantas que en invertebrados marinos) (Santafé, Pastrana \& Quirós, 2016), sugiere que $I$. birotulata posiblemente introduce este tipo de esteroles a su organismo a través de la dieta, fundamentada principalmente en fitoplancton (Quirós, Medrano \& Santafé, 2017) realizando posteriores modificaciones estructurales.

Se evidenció que el extracto más activo frente al ABTS+ + fue el acuoso, esto posiblemente se debe a que en este extracto se encuentran los compuestos más polares, como polifenoles, a los que se les ha atribuido una elevada actividad antioxidante (Torres \& Ganoza, 2017).

En cuanto al extracto clorofórmico, se observó una actividad mucho menor en comparación con los extractos polares. Esto posiblemente debido a la presencia de compuestos químicos de polaridad mediana y baja, aunque estos valores pueden considerarse relevantes para extractos de polaridad intermedia (Santafé, Pastrana, \& Quirós, 2016). Si bien a los compuestos de polaridad media y baja no se les ha atribuido una marcada actividad antioxidante, algunos AGPI, los cuales se encuentran presentes en este organismo, han demostrado ser efectivos en el control de algunas enfermedades producidas por el estrés oxidativo (Cawood et al., 2010). Esta disminución en la actividad antioxidante también puede deberse a que en la metodología utilizada se emplearon solventes de polaridad alta (etanol y agua) factor que podría estar afectando la solubilidad del extracto y por ende su impregnación en el sustrato empleado para el análisis.

En el ensayo de actividad insecticida se pudo observar que el extracto acuoso mostró mayor inhibición a todas las concentraciones y todos los tiempos de ensayo comparado con el extracto metanólico. A concentraciones bajas $(1000 \mu \mathrm{g} / \mathrm{ml})$ y pasadas $48 \mathrm{~h}$ no se observaron diferencias significativas en la afectación larval entre ambos extractos. Sin embargo, estas diferencias empiezan a ser más notorias a medida que la concentración de los extractos aumenta y los tiempos de exposición del ensayo son cortos (24 h). Así hasta el punto de lograr el $100 \%$ de la afectación larval para el extracto acuoso a la concentración de $5000 \mu \mathrm{g} / \mathrm{ml}$ para los tres tiempos de exposición del ensayo. Deduciendo que en el extracto acuoso se encuentran compuestos con mayor capacidad de inhibir las larvas de $S$. frugiperda, esto podría ser utilizado con insecticida de origen natural para el control de esta plaga.

Si bien el extracto acuoso mostró los mejores resultados de afectación larval a las concentraciones y todos los tiempos de exposición del ensayo, se observó que existe una diferencia significativa entre la concentración más baja $(1000 \mu \mathrm{g} / \mathrm{ml})$ y todas las demás concentraciones de este extracto. En este mismo sentido, se observó que a concentraciones superiores a los $2000 \mu \mathrm{g} / \mathrm{ml}$, las variaciones en la afectación larval no son tan marcadas en ninguno de los tiempos de exposición del ensayo. Lo anterior exceptuando la concentración más alta (5000 $\mu \mathrm{g} / \mathrm{ml}$ ) en la que se observó una afectación larval del $100 \%$ a las $24 \mathrm{~h}$ de exposición. Esto evidenció que la concentración de $2000 \mu \mathrm{g} / \mathrm{ml}$ puede generar una afectación larval significativa a tiempos de exposición de $24 \mathrm{~h}$, siendo estas las posibles condiciones óptimas y favorables en cuanto a la eficiencia y menor utilización de recursos para una posible utilización de dicho extracto como insecticida natural.

Por su parte, en el extracto metanólico se observó que a concentraciones bajas la afectación larval no es altamente significativa. Sin embargo, a medida que se aumentó la concentración y los tiempos de exposición al ensayo 
aumentó la afección larval. Una característica importante que se logró observar es que a concentraciones superiores de $3000 \mu \mathrm{g} / \mathrm{ml}$ del extracto metanólico y tiempos de exposición de 48 h no se observó diferencias apreciables en el ensayo y cuando se aumentó el tiempo de exposición a $72 \mathrm{~h}$, se observó que el aumento en la afección larval no es significativamente grande a ninguna de las concentraciones. Por lo tanto, la mayor eficiencia en la afectación larval para el extracto metanólico se logró a una concentración de $3000 \mu \mathrm{g} / \mathrm{ml}$ y un tiempo de ensayo de $48 \mathrm{~h}$.

La selección de concentraciones y tiempos de exposición de los ensayos para los extractos acuoso y metanólico puede ser también justificada en razón a la longitud de las larvas afectadas. Lo anterior debido a que no se encontraron diferencias significativas en los tamaños de las larvas afectadas a ninguna de las concentraciones en ambos extractos. Dicho comportamiento podría ratificar que emplear concentraciones más altas que $2000 \mu \mathrm{g} / \mathrm{ml}$ para el acuoso y $3000 \mu \mathrm{g} / \mathrm{ml}$ para el metanólico generaría mayores gastos de materia prima que no se verían reflejados en mejores resultados.

El extracto acuoso es el que mejor produce el EAA en las larvas, también es el que generó mayor afectación larval. Esto podría suponer que este extracto posee compuestos que, en primer lugar, son capaces de afectar la larva sin inducir un elevado EAA en las mismas, comportamiento observado a concentraciones entre 2000 y $4000 \mu \mathrm{g} / \mathrm{ml}$, en las que no se superó el $50 \%$ del EAA, aunque se observó una afección larval bastante significativa. En segundo lugar, a compuestos que posiblemente inducen un elevado EAA en la larvas y por ende una afección larval total en el ensayo.

Comparados con estudios previos de actividad insecticida y antialimentaria (Rojano \& Montoya, 2007; Céspedes, Salazar, Martínez, \& Aranda, 2005), se puede afirmar que tanto el extracto acuoso como el extracto metanólico de I. birotulata se pueden considerar como promisorios y eficientes agentes agroquímicos para el control del gusano cogollero de maíz $S$. frugiperda, ya que ambos pueden producir afección larval a varias concentraciones y tiempos de exposición, además de inducir un importante efecto antialimentario.

Declaración de ética: los autores declaran que todos están de acuerdo con esta publicación y que han hecho aportes que justifican su autoría; que no hay conflicto de interés de cualquier tipo; y que han cumplido con todos los requisitos y procedimientos éticos y legales pertinentes. El documento firmado se encuentra en los archivos de la revista.

\section{AGRADECIMIENTOS}

Los autores agradecen a la Vicerrectoría de Investigación de la Universidad de Córdoba, Montería, Colombia, por la financiación del presente trabajo.

\section{RESUMEN}

Los mares ocupan aproximadamente tres cuartas partes de la tierra constituyendo el hábitat de una gran cantidad de especies de flora y fauna. Como parte de los organismos marinos, los phylum bioquímicamente más estudiados son Porífera, Cnidaria y más recientemente Ascomycota, de todos ellos se han aislado e identificado un gran número de compuestos químicos, los cuales han mostrado diferentes tipos de actividades biológicas, principalmente citotóxica, bactericida y antioxidante, entre otras. En esta investigación se estudió la esponja marina Iotrochota birotulata recolectada en Punta Bello-Córdoba en el Caribe colombiano lográndose determinar su perfil lipídico a partir del análisis de los correspondientes espectros de masas de sus compuestos constituyentes, fueron identificados 19 ácidos grasos, los cuales son reportados por primera vez para esta especie. Además fueron identificados 10 esteroles. Se encontraron ácidos grasos con cadenas carbonadas entre C15 y C27, mostrando una amplia diversidad estructural lo cual es característico del phylum porífera. En cuanto a los esteroles se encontraron estructuras principalmente con núcleos $\Delta^{5}$ y $\Delta^{7}$ que son los más abundantes en las esponjas. Se encontró moderada actividad antioxidante en la estabilización del catión radical ABTS $+\cdot$ y baja actividad en la estabilización del radical DPPH•, el mayor valor de inhibición se encontró en el extracto acuoso con un valor de $\mathrm{IC}_{50}$ de $43.9 \mu \mathrm{g} / \mathrm{ml}$ frente al catión radical ABTS+• mostrando que $I$. birotulata puede producir compuestos con moderada actividad antioxidante. En el ensayo de actividad insecticida, se encontró afectación larval en los extractos metanólico y acuoso en todas las concentraciones $\mathrm{y}$ en todos los tiempos de exposición evaluados frente a 
Spodoptera frugiperda, también se determinó que estos extractos inducen un efecto antialimentario en las larvas como parte del mecanismo insecticida. Se determinaron las condiciones y los tiempos de exposición óptimos para la mejor eficiencia del ensayo, las cuales fueron de 3000 $\mu \mathrm{g} / \mathrm{ml}$ y $48 \mathrm{~h}$ para el extracto metanólico y $2000 \mu \mathrm{g} / \mathrm{ml}$ y $24 \mathrm{~h}$ para el extracto acuoso, respectivamente. En conclusión, los extractos evaluados de I. birotulata mostraron moderada actividad antioxidante y buenas e interesantes actividades insecticida y antialimentaria.

Palabras clave: Iotrochota birotulata; actividad antioxidante; actividad insecticida; efecto antialimentario; ácidos grasos; Spodoptera frugiperda.

\section{REFERENCIAS}

Blunt, J., Copp, B., Munro, M., Northcote, P. \& Prinsep, M. (2017). Marine natural products. Natural Product Report, 34(3), 235-294.

Brown, J., Kesler, C., Neary, J., \& Fishman, L. (2001). Effects of marine sponge extracts on mitogen-activated protein kinase (MAPK/ERK1,2) activity in SW-13 human adrenal carcinoma cells. Toxicon, 39, 1835-1839.

Carballeira, N. (2008). New advances in fatty acids as antimalarial, antimycobacterial and antifungal agents. Progress in Lipid Research, 47, 50-61.

Carballeira, N., Maldonado, L., \& Porras, B. (1987). Isoprenoid fatty acids from marine sponges. Are sponge selective? Lipids, 22(10), 767-769.

Cawood, A., Ding, R., Napper, F., Young, R., Williams, J., Ward, M., ... Calder, P. (2010). Eicosapentaenoic acid (EPA) from highly concentrated n-3 fatty acid ethyl esters is incorporated into advanced atherosclerotic plaques and higher plaque EPA is associated with decreased plaque inflammation and increased stability. Atherosclerosis, 212(1), 252-259.

Céspedes, C., Salazar, R., Martínez, M., \& Aranda, E. (2005). Insect growth regulatory effects of some extracts and sterols from Myrtillocactus geometrizans (Cactaceae) against Spodoptera frugiperda and Tenebrio molitor. Phytochemistry, 66(20), 2481-2493.

Constantino, V., Fattorusso, E., \& Mangoni, A. (1994). Three new brominated and iodinated tyrosine derivatives from Iotrochota birotulata, a non-verongida sponge. Journal of Natural Products, 57, 1552-1556.

De la Ossa, M., López, J., Márquez, D., Martínez, A., \& Márquez, M. (2016). Biological activity of fraction from the marine sponge Iotrochota birotulata IN mammalian cell lines. Revista Cubana de Farmacia, 50(4), 1-16.
Dewey, A., Baughan, C., Dean, T., Higgins, B., \& Johnson, I. (2012). Eicosapentaenoic acid (EPA, an omega-3 fatty acid from fish oils) for the treatment of cancer cachexia. The Cochrane Library, 1, 1-38.

Drazen, J., Phleger, C., \& Nichols, P. (2008). Lipid, sterols and fatty acid composition of abyssal holothurians and ophiuroids from the North-East Pacific Ocean: Food web implications. Comparative Biochemistry and Physiology Part B, 151, 79-87.

Galeano, E. \& Martínez, A. (2007). Antimicrobial activity of marine sponges from Urabá Gulf, Colombian Caribbean Region. Journal de Mycologie Médicale, $17,21-24$.

Guevara, L., Amaro, M., Fariñas, M., López, R., \& D'Armas, H. (2016). Bioactividad de las esponjas marinas Cliona varians y Cinachyrella kuekenthali provenientes de Isla Larga, Bahía de Mochima, Estado Sucre, Venezuela. Revista Ciencia UNEMI, 9(20), 19-28.

Jiang, S., Li, X., Zhang, L., Sun, W., Dai, S., Xie, L. W. ... \& Lee, K. (2008). Culturable actinobacteria isolated from marine sponge Iotrochota sp. Marine Biology, $153,945-952$.

Jiménez, A., Rodríguez, L., Murillo, W., Méndez, J., \& Rueda, E. (2013). Actividad anti-alimentaria de metabolitos secundarios de residuos cítricos sobre Spodoptera frugiperda (Lepidoptera: Noctuidae). Revista Colombiana de Entomología, 39(1), 113-119.

Kanazawa, A. (2001). Sterols in marine invertebrates. Fisheries Science, 67, 997-1007.

Lawson, M., Bergquist, P., \& Cambie, R. (1986). The cellular localization of long chain fatty acids in sponges. Tissue \& Cell, 18(1), 19-26.

Li, L., Deng, H., Fu, J., Li, W., \& Proksh, P. (2005). 6-Hydroxi-4-en-3-one sterols from the marine sponge Iotrochota birotulata. Journal of Asian Natural Products Research, 7(2), 115-120.

Márquez, D., Márquez, M., Martínez, A., \& Thomas, O. (2011). Isolation of a Bromotyrosine Derivative Compound of a Bioactive Fraction from the Marine Sponge Iotrochota birotulata from the Urabá Gulf (Colombia). Latin American Journal of Pharmacy, 30(2), 392-396.

Pastrana, O., Santafé, G., \& Torres, O. (2016). Perfil de Ácidos Grasos y Evaluación de las Actividades Antioxidante y Antifúngica del Holotureo Isostichopus badionotus. Información Tecnológica, 27(3), 3-10.

Pérez, C., \& Guerrero, C. (2006). Ácidos grasos en la dieta diabetes mellitus e insulino resistencia. Revista de la Facultad de Medicina, 54(2), 134-142.

Quirós, J., Medrano, W., \& Santafé, G. (2017). Esponjas (Porifera: Demospongiae) de raíces sumergidas de 
Rhizophora mangle en la bahía de Cispatá, Córdoba, Caribe Colombiano. Revista Mexicana de Biodiversidad, $88,80-85$.

Rodríguez, W., Martínez, R., Wolgfan, C., Osorno, O., Zea, S., \& Duque, C. (2005). CIDO 13-Metílicos anoico: un nuevo ácido graso de la esponja marina Agelas sventres. Momentos de Ciencia, 2(1), 49-56.

Rojano, B., \& Montoya, S. (2007) Evaluación de isoespintanol aislado de Oxandra cf. xylopioides (Annonaceae) sobre Spodoptera frugiperda J. E. Smith (Lepidoptera: Noctuidae). Revista Facultad Nacional de Agronomía Medellín, 60(1), 3691-3702.

Salma, Y., Lafont, E., Therville, N., Carpentier, S., Bonnafe, M., \& Levade, T. (2009) The natural marine anhydrophytosphingosine, Jaspine B, induces apoptosis in melanoma cells by interfering with ceramide metabolism. Biochemical Pharmacology, $78,477-485$.

Santafé, G., Pastrana, O., \& Quirós, J. (2016). Actividad antioxidante del erizo de mar Mellita quinquiesperforata (Leske) e identificación de sus compuestos lipídicos mayoritarios. Actualidades Biológicas, 38(104), 15-22.

Torres, F., \& Ganoza, M. (2017). Etnobotánica y sistemas de extracción para compuestos fenólicos, actividad antioxidante y toxicidad de plantas de páramos y bosques nublados del norte peruano. Revista Peruana de Medicina Integrativa, 2(2), 101-109.

Valle, H., \& Santafé, G. (2009). Esteroles libres de la esponja marina Mycale laevis. VITAE, Revista de la Facultad de Química Farmacéutica, 16(1), 103-109. 